\title{
The epidemiology and experience of atopic eczema during childhood: a discussion paper on the implications of current knowledge for health care, public health policy and research
}

\author{
Mairéad Fennessy, Sue Coupland, Jennie Popay, Karen Naysmith
}

\begin{abstract}
Atopic eczema is a chronic skin condition affecting between $5 \%$ and $20 \%$ of children aged up to 11 years at one time or other. Research suggests that prevalence is increasing and various environmental factors have been implicated in the aetiology. While often seen to be a minor problem, research suggests that it can cause considerable disruption to the lives of children and their carers and involves significant cost for the family and health care systems. The current consensus is that the majority of cases of atopic eczema are most appropriately managed within primary care. However, management of the condition is problematic because diagnosis is often difficult. Consultations tend to focus on the physical aspects of the problems neglecting the psychosocial, while treatment remains mainly palliative and can be as diverse as the condition itself. More appropriate and effective primary care management and support for children with atopic eczema and their carers will only be developed if health professionals become more aware of the social context of the disease and the impact on the lives of those affected. Public health responses focusing on primary prevention are also needed. This paper reviews a diverse literature on the epidemiology of the condition, the way in which it affects the lives of children and their carers and the factors that shape their help seeking decisions. The aim is to contribute to a more substantial knowledge base for public health and primary care developments and to point to areas for future research

(F Epidemiol Community Health 2000;54:581-589)
\end{abstract}

National Primary Care

Research and

Development

Centre/Institute for

Public Health

Research and Policy,

University of Salford

Correspondence to:

Professor Popay, Institute for Public Health Research and Policy University of Salford,

4th Floor, Humphrey Booth

House, The Crescent,

Salford M5 4QA

(j.m.popay@salford.ac.uk)

Accepted for publication 17 February 2000

Atopic eczema is a chronic relapsing condition that is commonly seen in primary care. It is characterised by itching and redness of the skin and is most prevalent in early childhood. Health professionals may often regard it as a trivial problem that will go away, and it may be overshadowed by other related conditions, such as asthma. ${ }^{1}$ However, the symptoms of eczema range from a small mildly irritating patch to a more widespread and painful rash, which can be physically extrusive and painful and may persist for many years. People with atopic eczema may experience limited productivity and restricted social interaction because of disability or disfigurement despite considerable input from carers or health professionals. ${ }^{23}$ Atopic eczema may also entail a considerable economic burden. It has been estimated that over $£ 288$ million is spent annually in the UK on the treatment of childhood atopic eczema alone. ${ }^{4}$ Parents meet only one third of these costs the rest are health care costs. While some proportion of these costs are related to secondary care treatments, it is obvious that there is a considerable commitment of resources within primary care where most people accessing formal health care are seen.

In this context the rising prevalence of eczema reported in some research is a matter of particular concern, ${ }^{5}$ not only to people with atopic eczema and carers, but also to health services as they seek to respond appropriately and effectively to increased need and demand. ${ }^{6}$ This paper explores current research based knowledge about atopic eczema during childhood focusing, in particular, on the epidemiology and aetiology of the condition and the social and psychological impact on children and their carers. The implications for health policy and practice and for further research are considered.

\section{Methods}

The paper is based on a review of English language literature because resources would not permit extensive translation. Inevitably this has meant that some relevant literature has not been considered, in particularly the considerable French literature on atopic eczema. While this inevitably introduces some bias into the literature reviewed, we are not drawing definitive conclusions from this material. Rather, we discuss in a more general way the implications of the findings that have been identified for public health and health service policy, practice and research.
Additionally, it is important to emphasise that many of the studies referred to in this paper were based in a secondary care setting where more severe cases of eczema predominate. The findings may not, therefore, be straightforwardly generalised to other groups of children and other care settings. Nevertheless, it is argued that this literature does provide some important pointers to the eczema in a situation where research is limited. Additionally, the findings of these studies are relevant to primary care given that the care of possible experience of all children with atopic 
children with more severe eczema will be "shared".

The review was part of a pilot study of the needs of children with atopic eczema and their carers conducted within the National Primary Care $R \& D$ Centre programme based at the University of Salford that is described elsewhere. ${ }^{8}$ It did not involve a systematic search for research concerned with the effectiveness or efficacy of treatment options. These issues have recently been discussed elsewhere ${ }^{7}$ and a Review Group focusing on skin conditions has been established within the Cochrane Collaboration. Rather, the review addressed three questions: (1) what do we already know about population patterns of atopic eczema during childhood; (2) in what ways does atopic eczema affect the lives of children and their carers; and (3) what factors shape lay decision making about help seeking for formal and informal care.

Research addressing these broad questions involves a wide range of medical and social science disciplines and research methods. Consequently the literature review methodology was inclusive and thorough. It was not, however, "systematic" in the sense now used within the context of the evidence based health care movement where papers are selected for inclusion according to a methodological hierarchy, which gives precedence to randomised controlled trials

Searches were performed on MEDline and Bath Information and Data Services (BIDS) databases using the key terms "atopic eczema", "atopic dermatitis", "skin disease", "infantile eczema", "eczema”, "primary care”, "lay management" and "chronic illness". The time frame for the review was in large part dictated by the time periods covered by these electronic databases. However, we also included manual references identified through a number of key informants familiar with research in the childhood eczema field. In excess of 3800 references were initially identified, including research using both qualitative and quantitative methods. From this large number of publications around 100 were selected on substantive grounds-because they addressed one or more of the three questions directing the review. These were then critically appraised using the guidelines set out by Fowkes and Fulton. ${ }^{9}$ For the critical appraisal of qualitative research we have used the checklist presented in the Scottish Consensus Statement on Qualitative Research in Primary Health Care. ${ }^{10}$ The 18 studies assessed as meeting the quality criteria identified in these quidelines are shown in tables 1 and 2. These form the basis for the discussion in this paper but they are supplemented with insights gleaned from publications not readily amenable to the application of the quality guidelines. These are clearly identified. They include, for example, papers describing the experience and/or views of individual professionals and papers and/or books that are not empirically based.

The paper is divided into three sections. In the first section the epidemiology of childhood eczema is described, drawing particularly on the studies described in table 1. Section two considers research on the impact of eczema on children and those who care for them and the third section focuses on the process of lay help seeking, looking in particular at demand for primary care. These sections draw particularly on the studies described in table 2 . In the conclusions we highlight some of the implications of the review for primary care management of childhood atopic eczema and priorities for future research.

Epidemiology of childhood atopic eczema PREVALENCE AND INCIDENCE

Efforts to estimate the prevalence of atopic eczema are complicated because very few studies are based on community samples. The small size of samples in many studies, the lack of control groups, the use of ill defined selection criteria and the dominance of cross sectional, rather than longitudinal design also limit the generalisability of the findings. Additionally, difficulties arise in interpreting, combining and directly comparing findings across studies because of the diverse ways in which the disease has been defined, differences in the age ranges of the children studied and in the study methods used. ${ }^{11}{ }^{12}$ However, there are a number of very large scale longitudinal studies to draw on, particularly in the UK. Table 1 summarises the design and findings of the main studies identified as providing reliable prevalence/incidence estimates.

Williams argues that available population based research suggests a "cumulative prevalence of [atopic dermatitis] of between $5 \%$ and $20 \%$ by the age of 11 " in developed countries. ${ }^{13}$ A number of studies have reported an increasing prevalence of atopic eczema over the past three decades. ${ }^{11}{ }^{12}{ }^{14}$ Even allowing for changing diagnostic practices available figures do suggest an increase although the magnitude reported does vary. For instance, Ninan and Russel's longitudinal study of Scottish school children aged 8-13 years suggested an increase in the prevalence of eczema from $5.3 \%$ in 1964 to $12 \%$ in $1989 .{ }^{15}$ Similarly, Schultz et al in their Danish study using 592 like-sexed atopic twins, reported an increase of a similar magnitude in the prevalence of at risk children who developed atopic eczema between 0-7 years of age from $3 \%$ in the $1960-64$ birth cohort to $10 \%$ in 1970-74. ${ }^{16}$ In contrast, Taylor and colleagues, based on an analysis of data from the three British national birth cohorts-1946, 1958, 1970 - reported an increasing prevalence from $5.1 \%$ in 1946 , to $7.3 \%$ in 1958 , to $12.2 \%$ in $1970 .{ }^{14}$ However, each cohort study used slightly different methods of data collection. A history of eczema from birth was mainly determined by parental recall and in only one of the cohorts was the diagnosis validated against physicians' records. Surveys in other countries including Finland have reported a lower prevalence than that reported in these surveys. ${ }^{11} 17$

SOCIAL PATTERNING

Atopic eczema during childhood is one of the few health problems that show a reverse social class gradient. Williams et al found that 


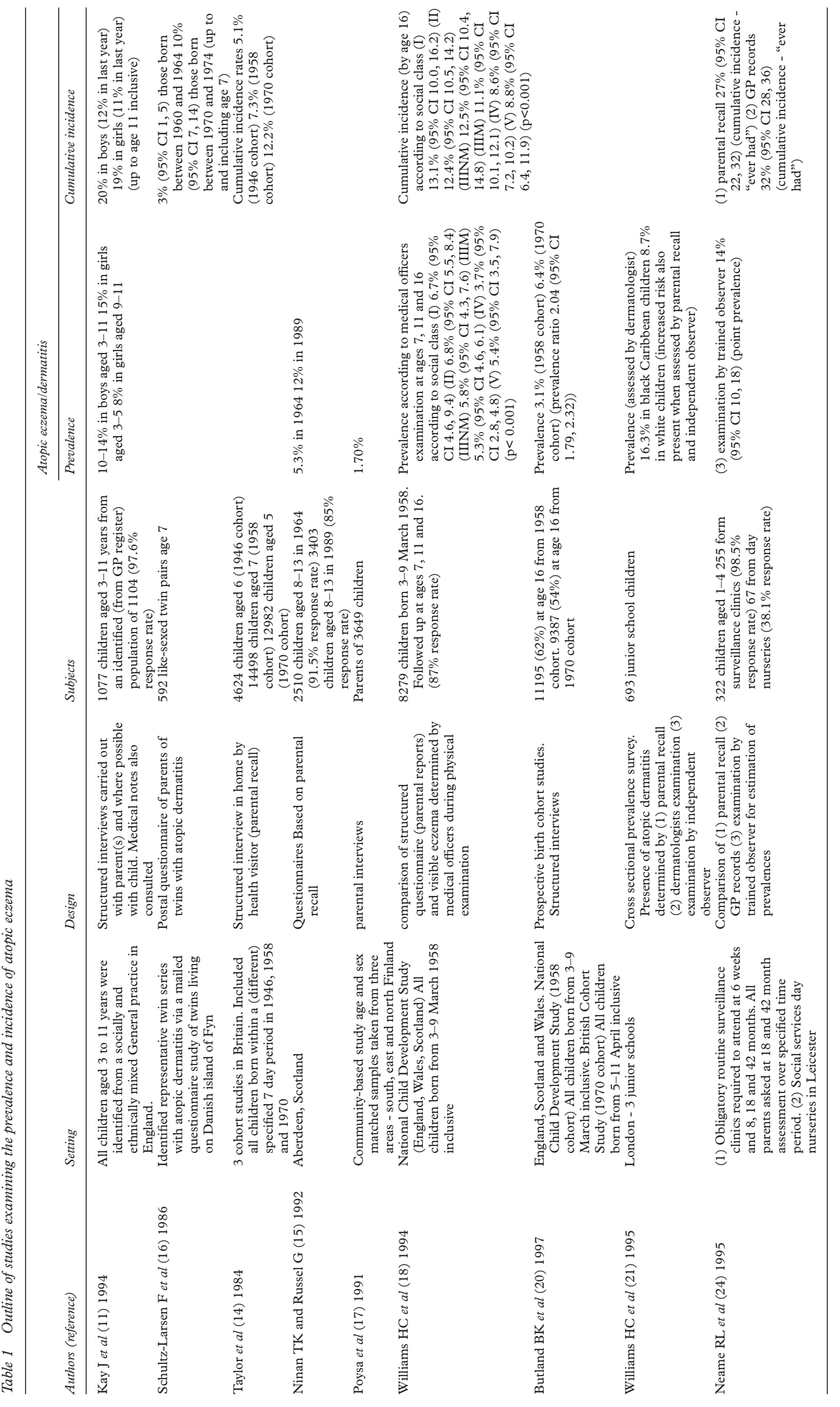




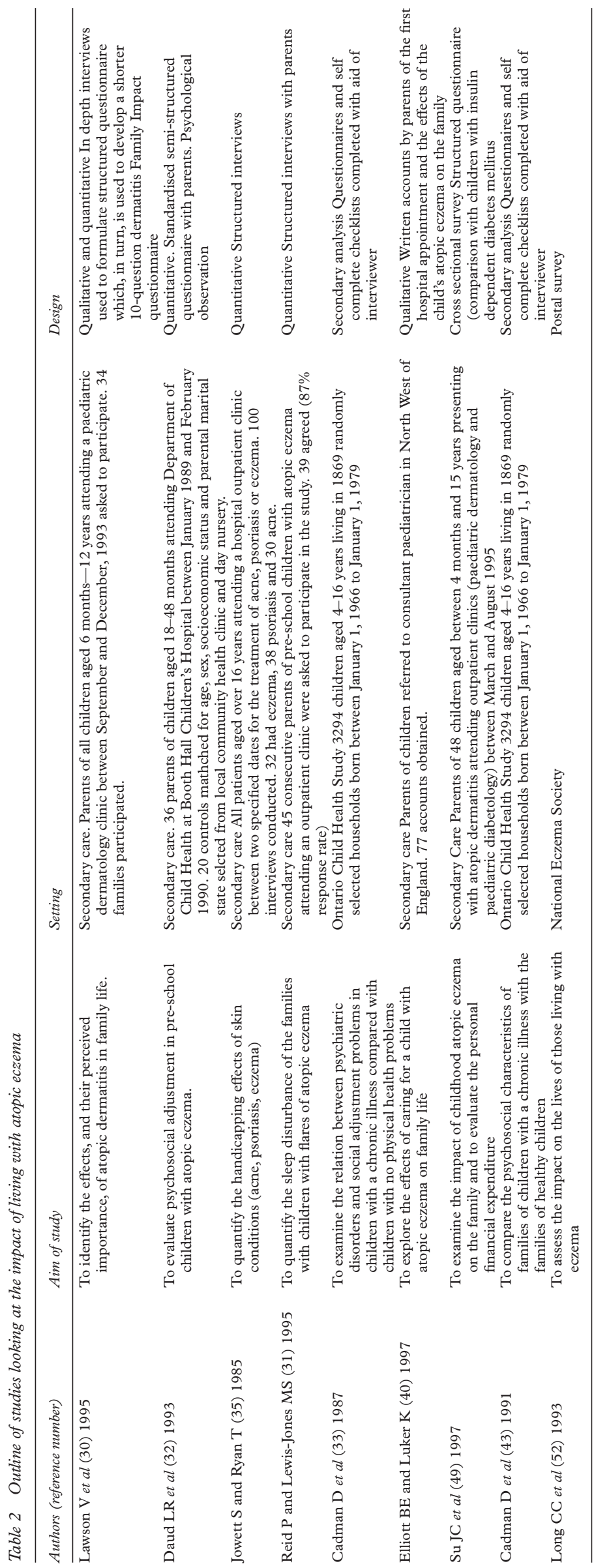

reported and examined eczema was almost twice as common in children in high socioeconomic groups among the 8279 children followed up at ages 7,11 and 16 in the UK 1958 National Child Development Study.

Although findings have not always been consistent, recent research has reported sex differences in atopic eczema. ${ }^{19}{ }^{20}$ Butland et $a l,{ }^{20}$ for example, found that at age $16,3.9 \%$ of females compared with $2.4 \%$ of males in the British birth cohort of 1958 and $7.8 \%$ of females compared with $4.9 \%$ of males in the British 1970 cohort had eczema. Research also suggests that the incidence of atopic eczema varies by age. In the UK figures from the National Child Development Study developed from the birth cohort of $1958^{21}$ suggest around 50 cases per 1000 in the first year of life, falling to 5 new cases per 1000 per year for the rest of childhood. ${ }^{13}$

There is some evidence that the incidence of atopic eczema is higher in developed countries, but that people from developing countries who move to industrialised areas may become more vulnerable than the local populations. For example, children of black Caribbean origin born in London have been shown to be at higher risk of atopic eczema than their white counterparts, ${ }^{22}$ with a prevalence (assessed by a dermatologist) of $16.3 \%$ and $8.7 \%$ respectively. Increases in the prevalence of atopic eczema have also been shown in studies of children from Tokelau who migrated to New Zealand and of Chinese immigrants in Hawaii compared with similar groups in their native country. ${ }^{23}{ }^{24}$ There is very little research exploring ethnic differences in the experience of atopic eczema during childhood within countries. However, a community study of 322 children in Leicester, England, found that there was no apparent ethnic difference in prevalence but that Asian children were three times more likely to be referred to secondary care than their white counterparts. ${ }^{25}$

AETIOLOGY

The aetiology of atopic eczema is complex. There is some evidence of genetic influences. For example, the Danish study by ShultzLarsen et al involving atopic twins found that among monozygotic twins there was $85 \%$ concordance compared with $21 \%$ for dizygotic twins. Fergusson et $\mathrm{l}^{26}$ interviewed the mothers of a birth cohort of 1265 infants delivered in maternity units in an urban region in New Zealand, supplemented by diaries kept by the mothers and by attendance records for the community nurse. This study found that the perinatal risk of atopic eczema was almost double for those children with a parental history of eczema compared with those with no parental history.

A number of environmental risk factors have also been implicated in the onset or exacerbation, or both, of atopic eczema, including house dust mites, pet dander, pollen, tobacco, air pollution and low humidity. ${ }^{13} 1927$ Factors, such as excessive use of soaps and other household irritants, are also thought to exacerbate the condition. ${ }^{13}$ The reverse social class gradient in 
relation to eczema mirrors that of asthma and may be linked to aspects of the home environment in higher socioeconomic groups, such as double glazing and fitted carpets, increased exposure to soaps and closer contact with pets. Additionally, Williams et $a l^{18}$ argue that prenatal factors, such as maternal diet and higher maternal age, could be factors in the reverse class gradient. It has also been argued that larger family sizes, with increased cross infection from siblings, may have a protective role in relation to atopic diseases. ${ }^{28}$

Food allergens have been reported as a trigger to, or exacerbating factor in, atopic eczema. However, evidence to support this is not strong. ${ }^{19}{ }^{27}$ The protective role of breast feeding in relation to atopic eczema has also been the subject of debate, with some studies finding that it has a beneficial effect ${ }^{2029}$ and others finding it has no protective, and perhaps even negative effect. ${ }^{1426}$

\section{Impact of living with atopic eczema}

IMPACT ON THE CHILD

Research suggests that the physical impact of atopic eczema during childhood varies with severity. Physical discomfort may have an important impact on the child's emotional and social development with long term implications.

Many of the studies referred to in the following section were based in secondary care settings. This may limit the generalisability of the findings to children with less severe eczema. However, the likelihood that children with severe eczema will be cared for in both primary and secondary care settings and, importantly in their homes, means that these results have broad relevance.

Sleep disturbance is common in pre-school children with reports of 10-30\% experiencing some sleep disturbance during their early years. ${ }^{30}$ However, the sleep disturbance experienced by children with atopic eczema is reported to be higher. ${ }^{30-32}$ Lawson et $a l^{30}$ in their study of 34 families with a child with atopic eczema, found that $63 \%$ of the children reported that they were experiencing sleep problems at that time and that most of their sample had done at some time. Another UK study by Daud and colleagues, ${ }^{31}$ using structured interviews with 39 parents of pre-school children, found that during flares $86 \%$ of the children experienced sleep disturbance. This dropped to $26 \%$ when the eczema was controlled. The samples for both these studies were taken from secondary care. However, it should not be assumed that children with less severe eczema suffer fewer sleep problems as we do not know what the threshold for sleep disturbance is. Even a mild itch may be enough to waken the child and cause sleep disruption.

Sleep disturbance may trigger other physical, emotional and social problems in children. Reid et $a l^{\beta 1}$ argue that disturbance in sleep patterns may affect the normal cyclic excretion of hormones, such as growth hormone, which could be partly linked to the small stature of some severely affected children. Lack of sleep may also lead to irritability, lack of concentra-

\section{KEY POINTS}

- Atopic eczema is a common childhood disease, the prevalence of which seems to be increasing. Despite this relatively little is known of its epidemiology, particularly the social patterning of eczema during childhood, or its physical, psychological and social impact on children and their carers.

- This paper reviews a diverse literature on: the epidemiology of childhood atopic eczema; the impact on children and their carers; and the factors shaping lay help seeking behaviour.

- It concludes that the currently research is limited but that the available evidence suggests that the atopic eczema during childhood may have more profound implications for the health and well being of children and their carers than is presently acknowledged by health care providers and public health policy.

- While most existing studies are based within secondary care settings, the majority of health service consultations for atopic eczema are within primary care. However, the bulk of care is provided in the home with relatively infrequent contact with services even in severe cases.

- Primary health care professionals (and parents) need to recognise the role of children in reporting on, and caring for, their own health. Children should be given choices and control over treatment options and settings.

- The review highlights the overall lack of community studies specific to childhood eczema. This dearth of research is likely to be linked to the apparently common assumption that it is a relatively minor self limiting condition. This is not supported by the, albeit limited, research on the social, developmental and economic impact of eczema for children and their families.

tion, inability to participate in leisure activities because of tiredness and decreased ability to function "normally". 3031

Other signs of psychological distress have been identified among children with atopic eczema. Another study by Daud et $a l^{32}$ involved 30 children (aged 18-48 months) with eczema attending an outpatient clinic. Using observational methods they found a significantly higher level of dependency and clinginess among children with atopic eczema (50\%) compared with matched controls (10\%). Mild fearfulness was also significantly more common in the children with eczema (40\%) than in the control group (10\%).

Daud and colleagues dispute the notion suggested by some researchers, that eczematous children display more irritable and aggressive behaviour and note that the behavioural problems seen in the children in their study were of a mild nature. Lawson $\mathrm{et} \mathrm{al}^{30}$ in contrast, report that $54 \%$ of parents reported their child 
displayed behavioural disturbances including irritability, bad temper, and being hurtful to others. However, this study relied on parental reporting of these behaviours, in contrast with the observational techniques used by Daud et $a l$, and no control group was included.

Research on chronic illness during childhood suggests that there may be significant effects on children's social relationships and everyday activities. We have not identified any studies exploring these issues among children with atopic eczema. Indeed, it is important to emphasise that in relation to the impact of eczema during childhood, and the care and support needs associated with this condition, we have identified no studies that have explicitly sought to obtain the perceptions of children themselves. Despite this lack of research, it can be argued that children with significant eczema will have similar experiences as a result of actions taken to avoid exacerbating factors and restriction because of bandaging. For example, research suggests that children with chronic illness accompanied by physical limitations have more problems with social interactions with peers than healthy controls, or children with chronic illness with no physical disability. ${ }^{33}$

Children with atopic eczema may also face stigma and social distancing and this may lead to particular vulnerability. Research suggests that skin conditions carry a stigma in the community and are often perceived as contagious and dirty. ${ }^{34}{ }^{35}$ Children with severe eczema may also be given unpleasant nicknames. It has been argued that this can exacerbate feelings of rejection, vulnerability, low self esteem and stress. ${ }^{36}$ Facial eczema has been associated with particularly high levels of distress. ${ }^{37}$ It has also been reported that severe eczema can lead to children requiring specialised psychiatric treatment. $^{38}$

CARING FOR A CHILD WITH ECZEMA

Research has clearly demonstrated that chronic illness in childhood has a considerable influence upon family life and can significantly affect parents and carers. However, it is only recently that the literature on childhood atopic eczema has focused on the social and financial consequences of the disease for carers and other family members. ${ }^{39}$ Although very limited, this research does suggest that these wider impacts can be substantial. Elliot and Luker, ${ }^{40}$ for example, conducted a qualitative study of 77 mothers of pre-school children with atopic eczema referred to a consultant paediatrician in the north west of England. They reported an increase in the normal burden of washing, dusting and cleaning to avoid allergens such that families can feel that their lives have been taken over by this condition. Sleep disturbance among adults caring for children with atopic eczema has also been reported to be common, and some commentators have suggested that this is possibly the most stressful aspect of the experience of carers. ${ }^{41}$

Similarly, an Australian cross sectional comparative study of 48 children with atopic eczema and 46 with diabetes attending paedi- atric outpatient clinics concluded that childhood eczema has a profound social, personal, emotional and financial impact on families. ${ }^{39}$ The average daily treatment time for eczema was reported to be three hours. Additionally, families faced financial difficulties in terms of loss of income because of time off work, travelling costs to clinics, child care costs for siblings, specialist clothing, bedding and equipment.

Disruption to employment for parents caring for children with eczema is also reported to be common and studies have found that fewer mothers with children with atopic eczema take up outside employment or pursue leisure activities compared with mothers of children without such problems. ${ }^{32} 30$ The mothers in the study by Daud et al reported a lack of social support and a reluctance on the part of friends and families to babysit. ${ }^{32}$

While the problems experienced by the families of children with eczema may be considerable, research on the experience and impact of chronic illness among children highlights the need to avoid negative stereotyping of the families involved. For example, the "bleak" view of families of chronically sick children, commonly reported in many clinical studies has been challenged ${ }^{33} 42$ for basing pessimistic assessments on weak/inappropriate measures of family functioning. The large Canadian study by Cadmans et $a l^{33}$ of 1869 families compared and contrasted psychosocial characteristics of parents and family units of children with chronic illness or physical disability, with those of healthy children. No evidence was found to suggest that families with children with chronic health problems functioned any differently than families in the general population. Cadman $e t ~ a l^{43}$ found no increase in social isolation among parents of children with chronic health problems compared with those of healthy children, and the degree of social isolation varied greatly. There are other studies using different measures of family functioning, which support this view. ${ }^{44}$

It has also been suggested that a child's chronic health problem can have a positive influence on family functioning in that the illness performs a unifying function, mobilising a family to interact around a shared experience as well as providing positive roles for family members.

Access to good quality, relevant information pertaining to the seriousness of atopic eczema, problems likely to occur during the illness and its potential effects on the child and family's everyday life may help people to cope. No studies specific to the information needs of families caring for children with atopic eczema were identified. However, studies of families caring for chronically ill children have reported that parents who have access to information and have a good understanding of their child's condition have a stronger sense of control over their situation than those who do not. ${ }^{46}$ Health professionals have an important role in helping people access such information but these needs may not always be visible. For example, research on families with chronically ill children suggests that to "cope", families may con- 
struct "life as normal". ${ }^{47}$ Unfortunately, in projecting this image of "coping" or adapting, problems may become less visible to others, so limiting the amount of formal and informal support they might otherwise receive. ${ }^{48}$

\section{Use of formal and informal care}

Data from the Fourth National Survey of Morbidity in General Practice in the UK, which involves a large and representative sample of the population, suggest that reported consultation rates for eczema have doubled between 1981-1982 and 1991-2. ${ }^{49}$ Current estimates suggest that atopic eczema accounts for $30 \%$ of skin disorders seen by general practitioners in the UK and $10 \%$ to $20 \%$ of referrals to dermatologists. $^{50}$ It has been estimated that around $10 \%$ of childhood atopic eczema cases identified in the community are severe..$^{51}$ It is also clear from the limited research available, that regardless of the severity of the condition, the bulk, or "burden", of care for children with eczema is carried out at home with infrequent health service contact-either in general practice or a hospital setting - to establish treatment regimens. ${ }^{40}$

Given that a large amount of primary care practitioner time will be taken up with childhood eczema cases, and that most care is provided by families in the home, it is important to explore the type of care and support that children with eczema and their carers want and receive. However, as in other areas of eczema research, few good quality community based studies of children and/or parents perspectives on their health care and support needs and their use of formal and informal care have been identified.

The National Eczema Society in the UK carried out a study of members experience of care in the early $1990 \mathrm{~s}^{52}$ This study reported widespread dissatisfaction with the patient education and other information offered by the health service and with the lack of clarity around diagnosis. People wanted more information about the nature of the condition and how to maximise the effects of treatments. The response rate $(29 \%)$ for this study was, however, low and dissatisfaction with the information on offer and the experience of services were given as reasons for joining the National Eczema Society. Both of these factors would be expected to increase levels of dissatisfaction among those surveyed.

Making choices concerning when and where to seek health care is a complex social process linked to people's perceptions of health and illness in general and their past experience of services in particular. ${ }^{53}$ Research suggests that there can be a discrepancy between the meanings lay people attribute to their experience of illness and the perceptions of health professionals and that this can adversely affect help seeking. ${ }^{47}$ Research has found that there can be a lack of understanding by health workers of the impact of chronic illness in childhood on the family. ${ }^{53}$ It has, for example, been suggested that doctors frequently underestimate the effect of eczema on everyday life, and sufferers or their families often fail to request the infor- mation they need. ${ }^{54}$ There does seem to be a common assumption among health care professionals and the public that eczema is a minor skin complaint that can be managed at home. ${ }^{140}$ Such attitudes may make it difficult for people with eczema to call on others for support and care. These problems will be compounded by any uncertainty surrounding the diagnosis and management of eczema

Rashes in young children are very common, so atopic eczema is often subject to lay treatment. However, there is some evidence that aspects of lay care may be inappropriate. For example, Matthews ${ }^{55}$ acknowledges that parents and carers can gain great comfort and support in seeking advice about their child's eczema from their lay network. However, they also argue that this may initiate a long line of different treatments without giving any one a chance to work properly, so prolonging feelings of anxiety. Webber et a $\bar{P}^{6}$ suggest that inappropriate lay care may have potentially serious implications. They studied 73 children seen consecutively in a dermatology outpatient department. Although most of the children were classed as having mild flexural dermatitis, $71 \%$ had significant changes made to their diet before attendance. Almost all the diets were not professionally supervised and over half of the children had been started on the diet without any prior professional advice. Less than $10 \%$ reported any improvement from these diets, which included potentially harmful practices such as using un-boiled, un-pasteurised goat's milk and severely restricted dietary intake.

\section{Conclusions}

IMPLICATIONS FOR PROFESSIONAL PRACTICE AND HEALTH POLICY

This paper has highlighted the limited nature of community based studies of the impact of eczema on the social, emotional and physical well being of children and the people who care for them. However, the research identified suggests that these impacts are more significant than is often acknowledged by those providing health and social care in primary and secondary settings and those developing public health policy.

The research reviewed has also highlighted the dominant role of lay/family care in the management of atopic eczema during childhood. It also points to the contingent nature of the decisions that carers make about management strategies. These decisions are based on the severity of symptoms and the course of the disease, as well as on the ways in which different management options impact on carers and children's everyday lives. The extent to which parents are able and/or willing to change daily activities and routines, to revise expectations of what can feasibly be achieved in their lives and the lives of their children, or to call on the support of others will vary in complex ways. This will depend on the interaction between various social, material, emotional and psychological factors. It is not surprising then that lay ideas of appropriate interventions in relation to children's eczema may be very different to those of health service professionals. ${ }^{57}$ 
High quality and appropriate care will require that health service professionals take greater account than hitherto of the wider social, emotional and material impact of eczema on children and their carers/families. There is a strong case for a "family centred" approach to the care of children with atopic eczema. Primary health care professionalsand indeed parents-also need to recognise children as reporters of their own health who should be given choices and control over treatment options and treatment settings. In many contexts it is no longer appropriate to rely on proxies to represent the views and experiences of children..$^{56}$

There are also clear messages for public health policy from the research reviewed here. The salience of multi-sectoral partnerships to strategies to meet the needs of children with atopic eczema is highlighted by the evidence that eczema can have wide ranging impacts on children's well being and healthy development, including educational attainment. The existing knowledge on environmental risk factors for atopic eczema also has important implications for public health workers looking to develop and implement primary, secondary and tertiary prevention strategies.

IMPLICATIONS FOR RESEARCH

Good quality community studies on the social patterning and prevalence of childhood eczema are lacking. So too is research into the social, material and emotional impact of childhood eczema; the quality of life of the children and carers affected; their capacity to manage the condition; and the experience of primary care providers. The methods used within existing research are also limited. Few of the studies reviewed used qualitative research techniques. Inductive methods would allow the views of those being interviewed to emerge without being hindered by any pre-conceived ideas or categories, as may sometimes be the case with quantitative research. Observational studies would also provide an important perspective on children's experience. There is also an absence in the research reviewed of any work seeking the child's point of view. This is a general problem with research into the experience of health, illness and health care. There are, however, a number of important developments underway to provide more appropriate methods for exploring children views, which should help to remedy this situation. ${ }^{58} 59$

The limited nature of research on childhood eczema may be linked to the apparently widespread assumption that it is a relatively minor self limiting condition. The research reviewed here suggests that such assumptions need to be challenged. Given the evidence that the impact of childhood eczema may be considerable, that prevalence is increasing, and the demand within primary care is considerable, there is a strong case for qualitative research on the experience of childhood eczema among families living in diverse circumstances alongside large scale longitudinal epidemiological studies. Such research would provide much needed data to inform public health initiatives and the development of more appropriate and effective care and support for the children and families affected. Conflicts of interest: none.

1 Bridgeman A. Management of atopic eczema in the community. Health Visitor 1994;67:226-7.

2 Forsdyke H, Watts J. Skin care in atopic eczema. Prof Nurse 1994;10:36-40.

3 Burdette-Taylor S. Eczema, ichthyosis, psoriasis: conditions of cornification. Wound Management 1995;41:36-42.

4 Herd R, Tidman M J, Hunter JAA, et al. The economic burden of atopic eczema: a community and hospital-based assessment. Br f Dermatol 1994;131 (suppl 44):34.

5 Lawton S. Living with eczema: The dermatology patient. $\mathrm{Br}$ 7 Nursing 1996;5:606-9.

6 Fitton F, Temple B, Acheson H. The cost of prescribing in general practice. Soc Sci Med 1985;21:1097-105.

7 Friedmann PS. ABC of allergies, allergy and the skin. II-Contact and atopic eczema. BMF 1998;316:1226-9.

8 Coupland S, Fennessy M. A pilot study of the role of primary care in the management and support of children with atopic eczema. Salford: National Primary Care Research and Development Centre, University of Salford, 1998.

9 Fowkes FGR, Fulton, PM. Critical appraisal of published Fowkes FGR, Fulton, PM. Critical appraisal of published
research: introductory guidelines. BMF 1991;302:1136-40.

10 Dowell J, Huboy G, Smith C. Scottish Consensus Statement on Qualitative Research in Primary Health Care. Dundee: Qualitative Research in Primary Health

11 Kay J, Gawkrodger DJ, Mortimer MJ, et al. The prevalence of childhood atopic eczema in a general population. $f \mathrm{Am}$ Acad Dermatol 1994,30:35-9.

12 Williams HC. Is the prevalence of atopic dermatitis increasing? Clin Exp Dermatol 1992;17:385-91.

3 Williams HC. On the definition and epidemiology of atopic dermatitis. Dermatol Clin 1995;13:649-57.

14 Taylor B, Wadsworth J, Wadsworth M, et al. Changes in the reported prevalence since the 1939-45 war. Lancet 1984;i: 465-71

15 Ninan TK, Russell G. Repiratory symptoms and atopy in Aberdeen schoolchildren : evidence from two surveys 25 years apart. BMF 1992;304:873-5.

16 Schultz-Larsen F, Holm NV, Henningsen K. Atopic dermatitis. A genetic-epidemiological study in a population-based twin sample. F Am Acad Dermatol 1986;15:487-94.

17 Poysa L, Korppi M, Pietikainen M, et al. Asthma, allergic rhinitis and atopic eczema in Finnish schoolchildren and adolescents. Allergy 1991;46:161-5.

18 Williams HC, Strachan DP, Hay RJ. Childhood eczema: disease of the advantaged? BMJ 1994; 308:1132-5.

19 Schultz-Larsen F. The epidemiology of atopic dermatitis. In: Burr ML, ed. Epidemiology of clinical allergy. Monogr Allergy. Basel: Karger, 1993;31:9-28.

20 Butland BK, Strachan DP, Lewis S, et al. Investigation into the increase in hayfever and eczema at age 16 observed between the 1958 and 1970 British birth cohorts. BMF 1997;315:717-21.

21 Shepherd PM. The national child development study: an introduction to the origins of the study and the methods of data collection. London: NCDS User Support Group, City University, 1985.

22 Williams HC, Pembroke AC, Forsdyke H, et al. Londonborn black Caribbean children are at increased risk of atopic dermatitis. F Am Acad Dermatol 1995;32:212-17.

23 Waite DA, Eyles EF, Tonkin SL, et al. Asthma prevalence in Tokelauan children in two environments. Clin Allergy Tokelauan ch: 10:71-5.

24 Worth RM. Atopic dermatitis among chinese infants in Honolulu and San Francisco. Hawaii Med F 1962;22:31-6.

25 Neame RL, Berth-Jones J, Kurinczuk JJ, et al. Prevalence of atopic dermatitis in Leicester: a study of methodology and examination of possible ethnic variation. $\mathrm{Br} \mathcal{F}$ Dermatol 1995;132:772-7.

26 Fergusson DM, Horwood LT, Shannon FT. Risk factors in childhood eczema. $\mathcal{F}$ Epidemiol Community Health. 1982;36: $118-22$.

27 Platt-Mills TAE, Mitchell EB, Rowntree S, et al. The role of dust mite allergens in atopic dermatitis. Clin Exp Dermatol 1983;8:223-47.

28 Stracken DP. Hay fever, hygiene and household size. BMF 1989;299:1259-60.

29 Atherton DJ. Breast feeding and atopic eczema. BMF. 1983; 287:775-6.

30 Lawson V, Lewis-Jones MS, Reid P, et al. Family impact of childhood atopic eczema. Br F Dermatol 1995;133 (suppl 45): 19

31 Reid P, Lewis-Jones $M$. Sleep difficulties and their management in preschoolers with atopic eczema. Clin Exp Dermatol 1995;20:38-41.

32 Daud LR, Garralda ME, David TJ. Psychosocial adjustment in preschool children with atopic eczema. Arch Dis Child 1993;69:670-6.

33 Cadman D, Boyle M, Szatmari P, et al. Chronic illness, disability and mental and social well-being: findings of the Ontario Child Health Study. Pediatrics 1987;79.805-13.

34 Anderson E. Caring for a child with eczema. F Clin Nursing 1981;1:984-7.

35 Jowett $S$, Ryan T. Skin disease and handicap: an analysis of the impact of skin conditions. Soc Sci Med 1985;20:425-9.

36 David TJ. The overworked and fraudulent diagnosis of food allergy and food intolerance in children. $f R$ Soc Med 1985; 78 (suppl 5):21-31. 
37 Jacobs B, Green J, David TJ. Self Concept of children with atopic dermatitis. Br F Dermatol 1996;133 (suppl 45):19. 38 Gupta M, Gupta A. Psychodermatology: An update. $\mathcal{F}$ Am Acad Dermatol 1996;34:1030-46.

39 Su J, Kemp AS, Varigos G, et al. Atopic eczema: it's impact on the family and financial cost. Arch Dis Child 1997;76 159-62.

40 Elliott BE, Luker $\mathrm{K}$. The experiences of mothers caring for a child with severe atopic eczema. F Clin Nursing 1997;6:241-7.

41 David TJ. The investigation and treatment of severe eczema in childhood. International Medicine Supplement 1983;6:1725.

42 Hobbs N, Perrin JM, Ireys HT. Chronically ill children and their families. London: JB Publications, 1985.

43 Cadman D, Rosenbaum P, Boyle M, et al. Children with chronic illness: family and parent demographic characteristics and psychosocial adjustment. Pediatrics 1991;87:884tics

44 Pless IB, Satterwhite BB. Family functioning and family problems, In: Haggerty RJ, Roghmann KJ, Pless IB, eds. Child heait $41-54$.

45 Hewitt S, Newson J, Newson E. The family and the handicapped child. Chicago: Aldine, 1970.

46 Canam C. Talking about cystic fibrosis with the family: what parents need to know. Issues in Comprehensive Paediatric Nursing 1986;9:167-8.

47 Anderson J M. The social construction of illness experience: families with a chronically ill child. F Adv Nurs 1981b;6: $427-4$
48 Robinson CA. Managing life with a chronic condition. Oualitative Health Research 1993;3:6-28.

49 Office of Population Censuses and Surveys. Morbidity statistics from general practice, 4th National Study 1991-1992. (t)

50 Rook AR, Savin JA, Wilkinson DS. The prevalence, incidence and ecology of diseases of the skin. In: Rook AR, Wilkinson DS, Ebling FJG, et al, eds. Textbook of dermatology. 4th ed. London: Blackwell, 1986.

51 Neame RL, Berth-Jones J, Graham-Brown RAC. A population based study of atopic dermatitis in the UK. [Abstract]. 7 Invest Dermatol 1993;100:543.

52 Long CC. What do members of the National Eczema Society Really Want? Clin Exp Dermatol 1993;18:516-22.

53 Shapiro J. Family reactions and coping strategies in response to the physically ill or handicapped child: a review. Soc $S c$ Med 1983;17:913-31.

54 Fitton F, Acheson H. Doctor-patient relationship: a study in

55 Matthews HJ. An eczema baby-is the mother's crisis recognised? Health Visitor 1984;57:116-17.

56 Webber, SA, Graham-Brown, RA, Hutchinson PE, et al. Dietary manipulation in childhood atopic dermatitis. $B r \mathcal{F}$

57 Reif L. Managing a life with chronic disease. Am f Nurs 1973;73:261-4.

58 Mahon A, Glendinning C, Clarke $\mathrm{K}$, et al. Researching children: methods and ethics. Children and Society 1996;10: 145-54.

59 Elliott E, Watson A. But the doctors aren't your mum. Health Matters 1997;30:8-9. 